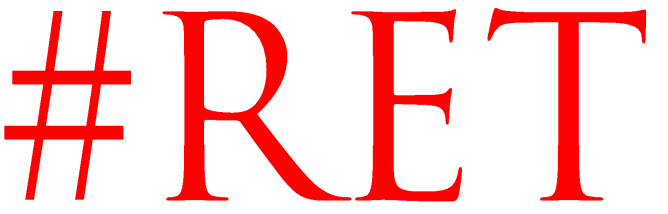

\title{
El trámite de alegaciones por parte de terceros en el derecho de acceso a la información pública
}

\author{
Severiano Fernández Ramos ${ }^{1}$ \\ Catedrático de Derecho Administrativo \\ Universidad de Cádiz \\ RECIBIDO: 1 de julio de 2020 \\ ACEPTADO: 15 de julio de 2020
}

RESUMEN: En este artículo se analiza la regulación y supuestos de aplicación del trámite de alegaciones por parte de terceros en el derecho de acceso, incluyendo el examen de todos los elementos procedimentales y efectos de su utilización.

PALABRAS CLAVE: Derecho de Acceso, Alegaciones, Trámite, Terceros afectados.

CONTENIDOS: 1. Funcionalidad del trámite de alegaciones. - 2. ¿Quiénes tienen derecho al trámite de alegaciones? - 3. Supuestos en los que puede válidamente omitirse. - 4. Notificación del trámite a los terceros. - 5. Suspensión del plazo para resolver. - 6. Notificación del trámite al solicitante. - 7. Efectos de la intervención (o su falta) de terceros afectados. - 8. Consecuencias de la omisión del trámite de alegaciones. - 9. Bibliografía.

Trabajo realizado en el marco del proyecto DER2016-77513-R: "Los retos de la gobernanza para el Derecho administrativo: buen gobierno y buena Administración: su proyección en las políticas públicas", Ministerio de Economia, Industria y Competitividad.

\footnotetext{
1 Catedrático de Derecho Administrativo de la Universidad de Cádiz. Cuenta con cuatro sexenios de investigación y ha desarrollado una intensa actividad investigadora en materia de transparencia y Buen Gobierno como antítesis a la corrupción. Es coautor (junto a José $M^{a}$ Pérez Monguió) de las siguientes monografias en la prestigiosa editorial Thomson ReutersAranzadi: La imparcialidad en el procedimiento administrativo (2012), La Ley de Transparencia, Acceso a la Información Pública y Buen Gobierno (2014), El Estatuto de los Altos Cargos (2016), El derecho de acceso a la información pública en España (2017), y Voz Pópuli. Consultas populares y procesos participativos (2019).
} 


\section{The processing of allegations by third parties on the right of access to public information}

ABSTRACT: This article analyzes the regulation and cases of application of the processing of claims by third parties on the right of access, including the examination of all procedural elements and effects of their use.

KEY WORDS: Right of Access, Allegations, Procedure, Affected third parties.

\section{Funcionalidad del trámite de alegaciones}

La Ley 19/2013, de 9 de diciembre, de transparencia, acceso a la información pública y buen gobierno (en adelante, LTAIBG) -art. 19.3- dispone lo siguiente: «Si la información solicitada pudiera afectar a derechos o intereses de terceros, debidamente identificados, se les concederá un plazo de quince días para que puedan realizar las alegaciones que estimen oportunas».

Como ha señalado la Comisión de Garantía del Derecho de Acceso a la Información Pública de Cataluña (en adelante, GAIP), este trámite de alegaciones tiene por finalidad permitir aflorar y justificar por parte de la persona afectada aquellas circunstancias personales $\mathrm{o}$ datos concretos y específicos que contenga la información que puedan ser determinantes de la aplicación de un límite o de su ponderación, no siendo relevante para el sentido de la resolución la mera expresión de disconformidad $u$ oposición de la persona afectada ${ }^{2}$. Pero, sin perjuicio de dicha innegable utilidad, su finalidad primaria no es otra que garantizar la posible defensa de sus derechos e intereses por parte de los terceros contrainteresados, en aras del principio contradictorio del procedimiento administrativo art. 75.4 Ley 33/2003, de 3 de noviembre, del Patrimonio de las Administraciones Públicas (en adelante, LPAC)- y, en última instancia, del derecho a la tutela judicial.

\footnotetext{
2 GAIP, Resolución de 7 de julio de 2016, de estimación de la Reclamación 32/2016. En este sentido, el Consejo de Transparencia y Buen Gobierno (en adelante, CTBG), R/0258/2016, 8 de septiembre, señala que el trámite de alegaciones "además de permitir obtener, en su caso, el consentimiento del interesado al acceso, permitiría el análisis de las circunstancias presentes en cada caso concreto y ponderar, adecuada y justificadamente, la incidencia en el derecho a la protección de datos de los interesados el acceso a la información solicitada".
} 
Por ello, se trata de un trámite, con las lógicas variantes, común en Derecho comparado3.

Más específicamente, el trámite del artículo 19.3 constituye una adaptación de la regla general de la LPAC -art. 8-, según la cual, si durante la instrucción de un procedimiento que no haya tenido publicidad en forma legal, se advierte la existencia de personas que sean titulares de derechos o intereses legítimos y directos «cuya identificación resulte del expediente y que puedan resultar afectados por la resolución que se dicte, se comunicará a dichas personas la tramitación del procedimiento», $y$, tal sentido, podrán ejercer los derechos procedimentales correspondientes, entre los cuales se encuentra el derecho a formular alegaciones -art. 76 LPAC-4. De este modo, el trámite de alegaciones del artículo 19.3 viene a cumplir para los terceros afectados en este procedimiento la doble función de llamada al procedimiento del artículo 8 LPAC y del trámite de audiencia -art. 82 LPAC-.

Asimismo, en el caso específico de datos personales no especialmente protegidos en el cual deba llevarse a cabo la ponderación de intereses ordenada en el artículo 15.3 LTAIBG, debe subrayarse la absoluta importancia de esta audiencia al tercero afectado titular de los datos personales. En puridad, esta audiencia es la garantía que sustituye en el caso de acceso a información pública el consentimiento del titular, ordenado con carácter general en el Reglamento Europeo de Protección de Datos -art. 6.1-. De aquí, además, la inconveniencia de aplicar el silencio estimatorio a este procedimiento, pues la simple inactividad del sujeto obligado lesionaría los derechos de terceros (tal como hemos defendido en otro lugar).

\footnotetext{
${ }^{3}$ Así, p. ej., en Italia, el D.P.R. 12 aprile 2006, n. 184, «Regolamento recante disciplina in materia di accesso ai documenti amministrativi», establece en su artículo 3 (que lleva por rúbrica: «Notifica ai controinteressati») lo siguiente: 1 . (...), la pubblica amministrazione cui è indirizzata la richiesta di accesso, se individua soggetti controinteressati, di cui all'articolo 22, comma 1, lettera c), della legge, è tenuta a dare comunicazione agli stessi, mediante invio di copia con raccomandata con avviso di ricevimento, o per via telematica per coloro che abbiano consentito tale forma di comunicazione. (...) Entro dieci giorni dalla ricezione della comunicazione di cui al comma 1, i controinteressati possono presentare una motivata opposizione, anche per via telematica, alla richiesta di accesso. Decorso tale termine, la pubblica amministrazione provvede sulla richiesta, accertata la ricezione della comunicazione di cui al comma 1». O, en Chile, la Ley 20.285 de 2008, dispone en su artículo 20: «Cuando la solicitud de acceso se refiera a documentos o antecedentes que contengan información que pueda afectar los derechos de terceros, la autoridad o jefatura o jefe superior del órgano o servicio de la Administración del Estado, requerido, dentro del plazo de dos días hábiles, contado desde la recepción de la solicitud que cumpla con los requisitos, deberá comunicar mediante carta certificada, a la o las personas a que se refiere o afecta la información correspondiente, la facultad que les asiste para oponerse a la entrega de los documentos solicitados, adjuntando copia del requerimiento respectivo».
}

4 Así, aun antes de la aprobación de la LTAIBG, defendimos este trámite en aplicación del antiguo artículo 34 Ley 30/1992, equivalente al actual artículo 8 LPAC. S. FERNÁNDEZ RAMOS (1997: 541). 


\section{2. ¿Quiénes tienen derecho al trámite de alegaciones?}

La LTAIBG -art. 19.3- delimita a los sujetos destinatarios de este trámite a partir de las siguientes referencias: «terceros», «debidamente identificados», cuyos «derechos o intereses» pudieran verse afectados por la información, en realidad, por la comunicación de la información.

La primera exigencia es que se trate de «terceros», noción que reitera dos veces la Ley: «terceros afectados»-art. 20.1-; oposición de «tercero»-art. 22.2-. Por tanto, ha de tratarse de personas ajenas a la relación que se entabla entre el solicitante y el sujeto obligado. A este respecto, en nuestra opinión, no deberían considerarse «terceros» los simples datos identificativos de autoridades y empleados públicos que constan en los documentos públicos cuando actúan en ejercicio de su función pública. Así, cuando se solicita el acceso a una licencia o a un acta de inspección o a un acta de un órgano colegiado, no debería ser necesario conceder audiencia a la autoridad que concedió la licencia, al inspector que levantó el acta o a los miembros del órgano colegiado, pues en propiedad no son «terceros», sino que actúan en nombre de la Administración o entidad obligada. Cuestión distinta es cuando el objeto mismo de la solicitud se refiere a información de las autoridades y agentes públicos (como puedan ser sus retribuciones), pues en tales casos sí es evidente que son los «terceros» afectados por la solicitud ${ }^{5}$.

En segundo lugar, en cuanto a la exigencia de que se trate de terceros «debidamente identificados», debe observarse que la LPAC -art. 8- se refiere a titulares de derechos o intereses legítimos y directos «cuya identificación resulte del expediente». Por tanto, debe entenderse que basta que del expedienté se infiera la identificación de los terceros. En ocasiones, la identificación será evidente. Así, si se solicita acceder a una solicitud, es claro que el tercero será la persona que presentó la solicitud y se dispondrá, además, del lugar o medio a efectos de notificaciones. Pero en otros casos, aunque se identifique el tercero, podrá ser más dificultosa la notificación6. Por su parte, es de interés la determinación de la Ley 19/2014 de Cataluña, que sustituye la expresión «terceros debidamente identificados» de la LTAIBG por afectados que «estén identificados o sean fácilmente identificables»-art. 31.1-, lo cual estimamos perfectamente compatible

\footnotetext{
5 Por ello discrepamos del criterio del Juzgado Central C-A n 6, sentencia 28/2018, de 6 de marzo, rec. 17/2017, cuando ante una petición de información sobre las retribuciones de los directivos de la CRTVE declara: «Tampoco resulta exigible la sustanciación de un trámite previo de alegaciones con los directivos cuyas retribuciones anuales se reclama conocer ex art. 19.3 de la ley citada, por cuanto no se justifica que la información solicitada pueda afectar a sus derechos o intereses, sin que tampoco resulte tal afectación del mero hecho del suministro del dato retributivo, o del puesto del organigrama que desempeña con la identificación de su perceptor».
}

${ }^{6}$ Así, PRIOR CABANILLAS (2019: 81), quien recuerda que, de acuerdo con la LPAC (art. 44), cuando los interesados en un procedimiento "sean desconocidos, se ignore el lugar de la notificación o bien, intentada ésta, no se hubiese podido practicar", la notificación se hará por medio de un anuncio publicado en el Boletín Oficial del Estado. Así, DE LA SERNA BILBAO (2017: 1271). 
con la ley básica, en la medida en que se trata de una norma más garantista, debido a su mayor flexibilidad7. Finalmente, desde un punto de vista terminológico, entendemos más adecuada la expresión «terceros afectados», que es la que emplea la Ley -art. 20.1-, en lugar de «terceros interesados», que encierra una cierta contradicción.

En tercer lugar, la exigencia de que se trate de terceros cuyos «derechos o intereses» ${ }^{8}$ pudieran verse afectados por la información, nos remite a los derechos e intereses privados protegidos por la Ley (legítimos): en primer lugar, el derecho a la protección de los datos personales, pero también los derechos a la propiedad intelectual o industrial, así como los intereses económicos y comerciales. El sujeto obligado debe, por tanto, realizar una valoración preliminar, para determinar la posible afección de dichos derechos e intereses y, en consecuencia, conceder el trámite de alegaciones.

Finalmente, debe destacarse que el inciso incluido en algunas leyes autonómicas, según el cual el traslado de la solicitud a los terceros afectados para formular alegaciones tendrá lugar «siempre que pudieran (las alegaciones) ser determinantes del sentido de la resolución»9, es manifiestamente contrario a la LTAIBG, la cual no condiciona dicho traslado a valoración alguna por parte del sujeto obligado: una vez identificado un posible interesado, en todo caso se le debe dar traslado de la solicitud.

\section{Supuestos en los que puede válidamente omitirse}

El artículo 19.3 LTAIBG parece dar a entender que la audiencia a terceros debe cumplirse en todo caso que «la información solicitada pudiera afectar a derechos o intereses de terceros». De entrada, debe precisarse que la afección no la produce la información, sino su comunicación al solicitante. Con todo, puede entenderse que este trámite es innecesario en determinados supuestos. Así, siguiendo parcialmente la esclarecedora exposición de la GAIP, el órgano competente para resolver una solicitud de información pública puede motivar razonadamente la omisión del trámite de alegaciones en determinados supuestos ${ }^{10}$ :

- Cuando el sujeto obligado acuerde aplicar una causa de inadmisión o de reenvío de la solicitud, pues en tal caso no existe posibilidad de perjuicio a terceros, al no existir pronunciamiento sobre el fondo. Asimismo, la GAIP entiende también innecesario el trámite cuando el órgano competente para

\footnotetext{
7 En igual sentido, Ley 1/2018 Cantabria -art. 14.1-.

8 Obsérvese que, a diferencia del artículo 8 LPAC, la LTAIBG no exige que se trate de intereses «directos».

9 Ley 4/2013 Extremadura -art. 22.1-; Ley 19/2014 de Cataluña -art. 31.1-. La Ley Foral 11/2012 Navarra -art. 29- contenía también esta exigencia, que acertadamente no se contempla ya en la Ley Foral 5/2018 -art. 39.1-.

10 GAIP, Dictamen 1/2016, de 11 de mayo, "Consulta general sobre accesibilidad a proyectos técnicos y otros documentos incluidos en los expedientes de licencias, control de actividades y contratación".
} 
resolver considere que hay motivos para denegar el acceso solicitado, ya que si no hay acceso no puede haber afectación de derechos o intereses de terceras personas. Y, como hemos indicado antes, la afección se produce por la comunicación. Sin embargo, en caso de una ulterior resolución estimatoria por parte del Consejo de Transparencia y Buen Gobierno (en adelante, CTBG), los tribunales están apreciando la comisión de una irregularidad procedimental. Cuestión distinta es que, como se defiende más adelante, esta irregularidad sea subsanable en el procedimiento de reclamación.

- Cuando las personas afectadas no estén identificadas (es decir, que no consten en la solicitud de acceso o en la información solicitada) o sea difícil identificarlas o localizarlas (es decir, que no se puedan identificar y determinar fácilmente con los archivos y bases de datos de la propia Administración). LO cierto es que en este supuesto falta el presupuesto previsto en la Ley.

- Cuando la solicitud de acceso pida información que debería haber sido objeto de publicidad activa, ya que la determinación legal de la publicidad hace que el trámite del traslado a los terceros afectados sea irrelevante a los efectos de incidir en la resolución, que en estos casos sólo puede ser favorable al acceso'1. Así, si una información de obligatoria publicación incluye necesariamente datos personales, no debería ser necesario abrir el trámite de alegaciones a los titulares. Eso sí, esta inclusión de los datos personales debe ser clara e inequívoca ( $p$. ej., la publicidad de las resoluciones de autorización o reconocimiento de compatibilidad a empleados públicos, únicamente tiene sentido si incluye la identidad del afectado; o la publicidad de los contratos estaría desdibujada si no incluyese la identidad del contratista, sea persona jurídica o física).

- Cuando se adopten precauciones para proteger los derechos o intereses afectados, tales como anonimizar o disociar datos personales, o limitar el acceso a vista sin copia de la información para evitar perjuicios a los derechos de explotación de propiedad intelectual, por ejemplo. Así, si se toma la referencia del artículo 8 LPAC, que impone la llamada a los terceros cuando «puedan resultar afectados por la resolución que se dicte», puede convenirse que no es necesario cumplir esta exigencia cuando la resolución es desestimatoria. Ahora bien, en nuestra opinión, en tal caso la denegación no podrá fundamentarse en la defensa de derechos e intereses de un tercero al que no se le ha dado la oportunidad de intervenir. Para obviar la llamada al tercero, entendemos que la resolución denegatoria deberá fundamentarse en una causa de inadmisión, o en un límite de interés público, de tal modo que haga innecesaria la audiencia a terceros ${ }^{12}$.

\footnotetext{
11 Como señala con acierto la GAIP, dado que en tales casos la determinación del legislador comporta por sí sola la prevalencia de los intereses públicos favorables al acceso, por encima de los privados favorables a la protección de los datos concernidos, aun cuando una determinada información afecte a derechos o intereses de terceros, el traslado de la solicitud a éstos es innecesario, ya que el legislador ha determinado que prevalece la publicidad por encima de lo que pueda resultar de las alegaciones de las terceras personas afectadas. Así, GAIP, Resolución de 7 de julio de 2016, de estimación de la Reclamación 19/2016. En puridad, no pude hablarse de afección de derechos e intereses de terceros, puesto que es la Ley la que los configura.
}

12 J. MESEGUER YEBRA (2014C: 355) considera que es un remedio "económico" en términos procedimentales y de plazo. 
- La GAIP añade cuando la información solicitada sólo afecte datos personales meramente identificativos relacionados directamente con la organización, el funcionamiento o la actividad de la Administración, ya que en estos casos la legislación de transparencia establece la regla general del acceso (art. 15.2 LTAIBG), lo que permite presumir que no hay afectación significativa de datos personales que pueda justificar la necesidad de dar traslado de la solicitud a las personas identificadas. Así, la GAIP considera que éste sería el caso, por ejemplo, del nombre de los empleados públicos que constan en los expedientes (organización), de los que han presentado alegaciones en un procedimiento de información pública (funcionamiento) o de los titulares de licencias (actividad). Como ya señalamos antes, en nuestra opinión, al menos, no deberían considerarse terceros a estos efectos los meros datos identificativos de autoridades y agentes públicos que constan en los documentos públicos cuando actúan en ejercicio de su función pública. En cambio, nos parece más cuestionable la omisión del trámite en los otros dos supuestos defendidos por la GAIP, cuando afectan a terceros ajenos al sujeto obligado, pues la Ley -art. 15.2- no impone, como nos consta, la comunicación en todo caso, sino una regla general.

- Cuando el solicitante acredite la conformidad de los terceros afectados, tal como se ha defendido antes, tal como prevé expresamente la Ley 4/2016 Castilla- La Mancha -art. 32.3-.

\section{Notificación del trámite a los terceros}

Respecto al momento de efectuar la audiencia, el CTBG ha expresado que el trámite deberá llevarse a cabo en los dias inmediatamente posteriores a la recepción de la solicitud de información ${ }^{13}$. Sin embargo, estimamos que es más exacto precisar que debe efectuarse tan pronto se haya procedido a la admisión a trámite de la solicitud. A este respecto, el Decreto Consell C. Valenciana 105/2017 art. 52.1- establece que el trámite de audiencia a las personas afectadas debe efectuarse en el plazo de 10 días hábiles desde la recepción de la solicitud, si bien debe entenderse que su incumplimiento no comporta consecuencias relevantes.

En cuanto al modo de efectuar esta audiencia a terceros, aunque la LTAIBG no lo explicite, parece indudable que, para poder formular alegaciones en defensa de sus intereses, los terceros deberán conocer el contenido exacto de la petición, esto es la información solicitada. Más aún, en el caso de que la solicitud incluya una motivación, entendemos que también deberá facilitarse a los terceros, con objeto de que puedan valorar su posición ante la solicitud con todos los elementos de juicio disponibles. En cambio, no parece que, inicialmente, se daba trasladar a los terceros la identidad del solicitante. Ciertamente, la LTAIBG no ha recogido la posibilidad prevista en el Convenio núm. 205, según el cual las Partes pueden otorgar a los solicitantes el derecho a mantener su anonimato, excepto cuando la identificación sea esencial para procesar la petición -art. 4.2-. Ahora bien,

13 CTBG y AEPD, Criterio interpretativo conjunto 001/2020, de 5 de marzo, «Información pública referida al personal que ocupa o ha ocupado un puesto de carácter eventual en la Administración General del Estado y aplicación del art. 19.3 de la LTAIBG». 
entendemos que, si la solicitud no incluye una motivación fundada en la posición jurídica del solicitante, la identidad del solicitante es irrelevante a efectos del trámite de alegaciones, pues la ponderación se mantiene bajo parámetros objetivos. En cambio, si la solicitud incluye una motivación fundada en la posición jurídica cualificada del solicitante (no uti cives), la identidad de éste sí podrá ser relevante a efectos de determinar la pertinencia de la motivación de la solicitud. Y, por tanto, en este caso sí deberá notificarse a los terceros la identidad del solicitante. Y ello, como indica la GAIP, salvo en casos excepcionales en los cuales el solicitante aporte algún elemento adicional que justifique garantizar su anonimato (p. ej., que se trate de un trabajador de la entidad afectada) ${ }^{14}$.

Por su parte, la Ley 19/2014 de Cataluña -art. 31.3- precisa que el traslado de la solicitud debe indicar los motivos de la solicitud, si se han expresado, pero no es obligatorio revelar la identidad del solicitante15. Más cuestionable es la Ley 1/2018 Cantabria -art. 14.2-, la cual establece que el traslado de la solicitud deberá indicar los motivos de la misma, si se han expresado, «sin revelar la identidad del solicitante», pues -como señalamos antes- en caso de motivación de la solicitud en la posición cualificada del solicitante, debería comunicarse tal identidad.

\section{Suspensión del plazo para resolver}

La LTAIBG -art. 19.3- establece lo siguiente: «El solicitante deberá ser informado de esta circunstancia (la concesión a terceros de un plazo de alegaciones), así como de la suspensión del plazo para dictar resolución hasta que se hayan recibido las alegaciones o haya transcurrido el plazo para su presentación». Debe observarse que la LPAC -art. 82- no contempla la suspensión del plazo de resolución en relación con el trámite de audiencia. No obstante, podría tener un cierto apoyo en la LPAC -art. 22.1.a)- («Cuando deba requerirse a cualquier interesado para la subsanación de deficiencias y la aportación de documentos y otros elementos de juicio necesarios»)16. Se trata, en todo caso, de una especialidad del procedimiento establecido en la LTAIBG. Sucede, sin embargo, que esta circunstancia será, previsiblemente, muy frecuente, lo que supone, de hecho, que el plazo de resolución sea muy superior al inicialmente previsto de un mes.

De la Ley parece desprenderse que la suspensión se produce automáticamente, a diferencia de los principales motivos de suspensión previstos en la LPAC -art. 22.1, «se podrá suspender»-. Asimismo, debe entenderse que la suspensión se produce

14 GAIP, Dictamen núm. 4/2016, Consulta general relativa a la posició que ocupen els prestadors privats de serveis públics de l'article 3.1.d de la Llei 19/2014 en el procediment d'accés a informació que es troba en el seu poder. Con todo, discrepamos del criterio de la GAIP, según el cual, salvo que el solicitante lo justifique debe trasladarse la identidad del mismo a los terceros.

15 En cambio, no es conforme a la LTAIBG la reducción del plazo para formular alegaciones de 15 a 10 días contenida en la Ley 19/2014 de Cataluña -art. 31.1-

16 Por ello no podemos compartir la opinión de L. PÉREZ SARRIÓN (2014: 181) quien considera esta regla «un juego frivolo de carga del recurso entre los titulares de los dos derechos enfrentados». 
desde la fecha en que es notificado al tercero el trámite de alegaciones, lo que suscita la cuestión de ¿qué sucede en los casos, en la práctica comunes, en los que el trámite de alegaciones se comunica a una pluralidad de terceros? En nuestra opinión, habrá que entender que el cómputo de la suspensión no se inicia hasta tanto no se produce la última notificación.

Más clara es la determinación de la fecha final: hasta que se hayan recibido las alegaciones «O» haya transcurrido el plazo para su presentación. De este modo, como es regla en la LPAC [p. ej., art. 22.1.a)], la suspensión cesa en el supuesto que las alegaciones se reciban antes de la finalización del plazo concedido al efecto y, en todo caso, una vez finalizado el plazo17. Asimismo, en aplicación de las reglas generales del procedimiento administrativo, el plazo de 15 dias debe entenderse que son hábiles -art. 30.2 LPAC-, lo cual supone un plazo excesivamente prolongado sólo para formular alegaciones ${ }^{18}$. Sin embargo, es cuestionable el plazo de 10 fijado en la Ley 19/2014 de Cataluña -art. 31.3-, pues supone recortar el plazo de la Ley básica (y ello aun cuando consideramos que éste es excesivo).

\section{Notificación del trámite al solicitante}

De cara al solicitante, la LTAIBG -art. 19.3- establece lo siguiente: «El solicitante deberá ser informado de esta circunstancia (la concesión a terceros de un plazo de alegaciones), así como de la suspensión del plazo para dictar resolución hasta que se hayan recibido las alegaciones o haya transcurrido el plazo para su presentación». Se trata de una nueva especialidad de este procedimiento, en relación con la cual cabe preguntarse, ¿cuál es la función de esta notificación? En nuestra opinión, es doble: de un lado, permitir al solicitante disponer de los elementos imprescindibles para realizar el cómputo del plazo para resolver, debido a la indicada suspensión del plazo; y, de otro lado, informar al solicitante sobre la posibilidad de formulación de alegaciones por parte de terceros, de tal modo que podrá valorar solicitar el acceso al expediente para conocer las mismas y, en su caso, formular nuevas alegaciones por su parte -art. 76.1-, todo ello sin perjuicio de la posibilidad de un ulterior trámite de audiencia de oficio al solicitante.

Establecido lo anterior, debe entenderse que esta notificación al solicitante debe producirse una vez notificado el trámite de alegaciones a los terceros, debiendo informar de la fecha de dicha notificación, pues de lo contrario sería superfluo el mandato de la LTAIBG según el cual la notificación debe incluir la información de la suspensión del plazo para dictar resolución. En cambio, entendemos que la notificación no debe indicar la identidad de los contra-interesados. En efecto, la Ley se limita a establecer que el solicitante deberá ser informado de esta

17 Asi ha tenido que recordarlo el CTBG, R/0184/2018, 26 de junio de 2018; R/0494/2018, 21 de noviembre de 2018 .

18 Piénsese que, en Italia, el D.P.R. 12 aprile 2006, n. 184, «Regolamento recante disciplina in materia di accesso ai documenti amministrativi», establece un plazo de diez días, y en Chile, la Ley 20.285 de 2008 establece que los terceros afectados podrán ejercer su derecho de oposición dentro del plazo de tres dias hábiles contado desde la fecha de notificación (art. 20). 
«circunstancia», es decir, del hecho de la apertura del trámite. Lo cierto es que, salvo que comparezcan en el trámite y formulen alegaciones, la identidad de los terceros no es inicialmente necesaria para el solicitante, e, incluso, puede formar parte precisamente del objeto de la solicitud.

Por lo demás, cabe preguntarse ¿qué sucede si el sujeto obligado omite esta notificación del trámite de alegaciones al solicitante? Aun cuando se trata de una evidente irregularidad procedimental, en nuestra opinión, es dudoso que cause indefensión al solicitante, lo cual no sucederá de ningún modo si el sujeto obligado concede trámite de audiencia al solicitante.

\section{Efectos de la intervención (o su falta) de terceros afectados}

Como en cualquier otro procedimiento administrativo, las alegaciones no vinculan al órgano competente para resolver, si bien deben ser tenidas en cuenta por aquél -arts. 76.1 y 88.1 LPAC-, tal como se ha señalado, para ponderar el test del daño y del interés público en la divulgación de la información. Ahora bien, como es lógico, este trámite no supone reconocer a los terceros interesados un derecho de veto a la comunicación de la información solicitada19. En este sentido, el CTBG ha declarado que las alegaciones de terceros deben ser adecuadamente valoradas por el órgano tramitador, que debe motivar su aplicación al procedimiento y, concretamente en el supuesto de una solicitud de acceso a la información, no puede suponer en ningún caso un derecho de veto a la concesión de la información solicitada 20.

Al mismo tiempo, si se cumple con el trámite de alegaciones, y el tercero afectado no se opone a la comunicación de la información ni formula alegación alguna, no cabe atribuir a esta omisión significado alguno, ni a favor ni en contra de la comunicación de la información, pues no es su función emitir declaraciones de voluntad, sino aportar elementos de juicio. Ahora bien, estimamos que este hecho, esto es la no intervención en el procedimiento, sí podrá ser objeto de ponderación por la autoridad competente: frente al interés público en la divulgación de información pública la persona potencialmente afectada en sus intereses particulares no opone objeción alguna. Todo ello, naturalmente, salvo en el

19 Vid. M. M RAZQUÍN LIZARRAGA (2015: 83); L. RAMS RAMOS (2016a: 30; 2016a: 589); PRIOR CABANILLAS (2019: 85).

20 CTBG, Resolución R/0147/2015, de 17 de julio de 2015, la cual añade: «De otro modo, nos encontrariamos con la circunstancia de que la mera negativa a suministrar la información por parte del tercero interesado, sin más argumentos por su parte, como ocurre en este caso concreto, nos llevaría a asumir tal negativa como un impedimento absoluto para suministrar la información, sin más argumento que dicho rechazo, veto o falta de autorización». En este sentido, el Criterio interpretativo conjunto del CTBG y AEPD 001/2020, de 5 de marzo, señala lo siguiente: «Ello implica que, cuando sea requerida dicha ponderación y no el consentimiento expreso del interesado, una negativa de éste a la cesión a un tercero de su información personal, si bien puede ser considerada como oposición al tratamiento de datos que implica la cesión de la información, tendrá los efectos que correspondan en la ponderación que el órgano competente haya de realizar en cada caso concreto. Todo ello sin que estos supuestos lleguen a equipararse al tratamiento de los datos especialmente protegidos». 
supuesto de datos especialmente protegidos, en el cual el consentimiento del afectado, como es bien sabido, debe ser expreso21.

Únicamente cabe pensar en una cierta vinculación del sujeto obligado a la decisión de la persona afectada en el caso de que ésta otorgue expresamente su aquiescencia a la comunicación de la información, y no exista ningún otro interés público o particular- implicado en la comunicación22. En todo caso, aun cuando las alegaciones formuladas por los contra-interesados no vinculan al sujeto obligado sobre el fondo del asunto, en caso de oposición de tercero, el acceso sólo tendrá lugar cuando, habiéndose concedido dicho acceso, la resolución sea firme -art. 22.2-.

De otro lado, destaca la determinación de algunas leyes autonómicas según la cual si el tercero no responde en el plazo requerido se presumirá que no está conforme con que se otorgue el acceso a la información solicitada ${ }^{23}$, para seguidamente añadir que el órgano competente, sobre la base de lo manifestado de forma expresa o presunta por los terceros, emitirá la resolución que estime procedente 24. Sin embargo, no se comprende bien la utilidad de esta regla, pues si la comunicación de la información requiere el consentimiento expreso del titular como sucede con los datos especialmente protegidos-, es innecesaria; y si tal consentimiento expreso no es preciso, la autoridad deberá resolver a las vista de las alegaciones y pruebas presentadas, sin que la presunción de la Ley autonómica aporte nada útil25.

\section{Consecuencias de la omisión del trámite de alegaciones}

En nuestra opinión, deben diferenciarse varias situaciones. Si la resolución dictada omitiendo el trámite de audiencia a terceros interesados es estimatoria de la solicitud, total o parcialmente, entendemos que sería inválida, por causar indefensión a los terceros. Asi debe recordarse la relevancia que la Ley concede a este trámite, pues, en caso de oposición de tercero, el acceso sólo tendrá lugar

\footnotetext{
21 PRIOR CABANILLAS (2019: 87).

22 Así, lo defendimos en S. FERNÁNDEZ RAMOS (1997: 542). Así, el Consejo de Transparencia y Protección de Datos de Andalucía, Resolución 42/2016, de 22 junio, concluye que "resulta evidente que si el tercero no se muestra concernido por la divulgación de la información no podría válidamente esgrimirse el límite que nos ocupa para denegar el acceso a una información que, en principio, ha de ser pública. Tan sólo cuando inequívocamente conste a la Administración la oposición del sujeto privado, y así pueda acreditarse ante este Consejo, podrá resolver directamente la petición de información con base en este límite sin necesidad de acudir previamente al art. 19.3 LTAIBG".

23 Ley Foral 5/2018 -art. 39.2- (y antes Ley Foral 11/2012 Navarra -art. 29-); Ley 1/2018 Cantabria -art. $14.2-$

24 Ley Foral 5/2018 -art. 39.3-; Ley 1/2018 Cantabria -art. 14.5-.

25 En este sentido, M. FERNÁNDEZ SALMERÓN (2014: 308) señala que es problemática la admisión de manifestaciones de voluntad tácitas. Curiosamente, la proposición de ley catalana optaba por la alternativa inversa, al prever que si el tercero no efectuaba alegaciones en este trámite se entendería que no se oponía al acceso a la información solicitada.
} 
cuando, habiéndose concedido dicho acceso, la resolución sea firme -art. 22.2-. Más aún, en el caso de afección de datos personales, dado que -como se ha dicho antes- la garantía de audiencia viene a sustituir la exigencia ordenada en el REPD de consentimiento del titular del dato, podría defenderse que la resolución es nula de pleno derecho, por omisión de un trámite esencial26.

Ahora bien, en el caso de que la resolución sea de inadmisión, como se señaló antes, el trámite de alegaciones era innecesario, de modo que, en puridad, no se comete irregularidad alguna. Por último, en caso de resolución desestimatoria, aun cuando es innegable la irregularidad, lo cierto es que no se ha producido perjuicio al tercero interesado. Cuando el solicitante formula la reclamación ante el órgano de garantía, y se evidencia la existencia de terceros sin que se haya cumplido el trámite de alegaciones (circunstancia que, en ocasiones, es alegada, en un alarde de cinismo, por el propio sujeto obligado incumplidor), el órgano de garantía tiene ante sí dos posibilidades. Una, ordenar la retroacción de las actuaciones, para que el sujeto obligado cumpla el trámite que indebidamente omitió (lo cual puede estimular el incumplimiento, pues, al fin y al cabo, el sujeto obligado podrá beneficiarse del mismo, utilizándolo medida dilatoria)27. Pero cabe también que el órgano de garantía dispense (como es su obligación -art. 24.3-) la audiencia al tercero interesado en el procedimiento de reclamación (en su caso, con la colaboración del sujeto obligado), pues en tal caso entendemos subsanado el defecto acaecido en el procedimiento de solicitud, pudiendo el órgano de garantía resolver sobre el fondo el asunto sin más dilaciones.

\footnotetext{
26 Asi lo ha entendido la Comisión de Transparencia de Castilla y León, Resolución 2/2016, de 16 de marzo.

27 Así, el CTBG suele ordenar la retroacción de las actuaciones, para que se cumpla con la audiencia al tercero y ello a pesar de que la resolución es denegatoria. P. ej., CTBG, R/0405/2016, 1 de diciembre de 2016. Igualmente, el Consejo de Transparencia y Protección de Datos de Andalucía (ej., Resolución 14/2016 y Resolución 20/2016, ambas de 24 de mayo de 2016) insiste en la necesidad de abrir el trámite de alegaciones a los terceros afectados para garantizar el derecho de defensa de sus intereses. En estos supuestos, tras comprobar que no se concedió el plazo de alegaciones a los afectados, el órgano de control andaluz resuelve las reclamaciones acordando retrotraer los procedimientos al momento en que debiera haberse otorgado el periodo de alegaciones, tras lo cual habrán de continuarse hasta dictarse la resolución correspondiente.
} 


\section{Bibliografía}

DE LA SERNA BILBAO (2017): «Comentario al numeral 3 del artículo 19 de la LT», en Troncoso, A. (dir.), Comentarios a la Ley 19/2013, de 9 diciembre. Transparencia, Acceso a la Información Pública y Buen Gobierno, Thomson Reuters pp. 1265 y ss.

FERNÁNDEZ RAMOS, S. (1997): El derecho de acceso a los documentos administrativos, Marcial Pons, Madrid.

FERNÁNDEZ RAMOS, S. - PÉREZ MONGUIÓ, J. M. (2017): El derecho al acceso a la información pública en España, Aranzadi-Thomson, Cizur Menor.

FERNÁNDEZ SALMERÓN M. (2014): "Procedimiento administrativo e información del sector público", VV., Régimen juridico de la transparencia en el sector público, Aranzadi-Thomson, Cizur Menor.

MESEGUER YEBRA (2014C): «Las "mejoras" autonómicas en la regulación del derecho de acceso a la información pública», Revista Andaluza de Administración Pública, núm. 90, pp. 337 y ss.

PÉREZ SARRIÓN, L. (2014): «El derecho de acceso de los ciudadanos a los expedientes y archivos administrativos», en VV. Implantación práctica de la Ley de Transparencia en los Ayuntamientos, El Derecho Editores, pp. 157 y ss.

PRIOR CABANILLAS, Julián A.: «El trámite de alegaciones y el efecto derivado de la oposición de terceros interesados al acceso a la información pública», en Comentarios sobre aspectos clave en materia de acceso a la información pública, Volumen II, FEMP, pp. 79-98.

RAMS RAMOS, L. (2016): «El procedimiento de ejercicio del derecho de acceso a la información pública», Revista General de Derecho Administrativo, núm. 41.

RAZQUÍN LIZARRAGA, M. M. (2015): El derecho de acceso a la información pública. Teoria y práctica, en especial, para las entidades locales, IVAP, Oñati. 